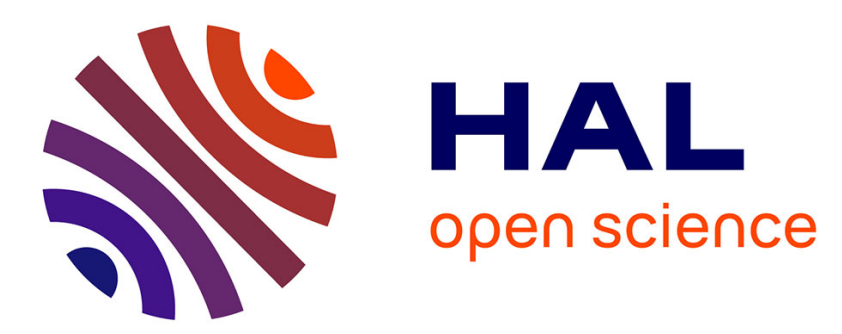

\title{
Modelling of the Deposition of Molybdenum on Silicon from Molybdenum Hexafluoride and Hydrogen
}

\author{
E. Orij, M. de Croon, G. Marin
}

\section{To cite this version:}

E. Orij, M. de Croon, G. Marin. Modelling of the Deposition of Molybdenum on Silicon from Molybdenum Hexafluoride and Hydrogen. Journal de Physique IV Proceedings, 1995, 05 (C5), pp.C5-331C5-338. 10.1051/jphyscol:1995539 . jpa-00253866

\section{HAL Id: jpa-00253866 https://hal.science/jpa-00253866}

Submitted on 1 Jan 1995

HAL is a multi-disciplinary open access archive for the deposit and dissemination of scientific research documents, whether they are published or not. The documents may come from teaching and research institutions in France or abroad, or from public or private research centers.
L'archive ouverte pluridisciplinaire HAL, est destinée au dépôt et à la diffusion de documents scientifiques de niveau recherche, publiés ou non, émanant des établissements d'enseignement et de recherche français ou étrangers, des laboratoires publics ou privés. 


\title{
Modelling of the Deposition of Molybdenum on Silicon from Molybdenum Hexafluoride and Hydrogen
}

\author{
E.N. Orij, M.H.J.M. de Croon and G.B. Marin \\ Eindhoven University of Technology, Laboratorium voor Chemische Technology, P.O. Box 513, \\ $5600 \mathrm{MB}$ Eindhoven, The Netherlands
}

\begin{abstract}
The deposition of molybdenum on silicon from $\mathrm{MoF}_{6}$ and $\mathbf{H}_{2}$ is studied using a microbalance setup. The deposition rate is time dependent, which is explained by the significant contribution of the reduction of $\mathrm{MoF}_{6}$ by $\mathrm{Si}$. A model taking into account both deposition routes and in particular diffusion of $\mathrm{Si}$ through the growing layer allows to describe the observations quantitatively. The relative importance of two routes was assessed and the kinetics of the reduction by $\mathrm{H}_{2}$ could be distinguished from the overall growth kinetics. A partial reaction order of 1.4 in hydrogen was found for the reduction of $\mathrm{MoF}_{6}$ by $\mathrm{H}_{2}$. The order in $\mathrm{MoF}_{6}$ is negative.
\end{abstract}

\section{INTRODUCTION}

The low pressure chemical vapour deposition of molybdenum and tungsten from molybdenum hexafluoride and tungsten hexafluoride provides a relatively low-temperature process for use in VLSI-level metallization. Although molybdenum has similar characteristics, W-LPCVD has received much more attention in the last decade: only a few studies report about the reduction of $\mathrm{MoF}_{6}$ by hydrogen and/or silicon [1-5]. Lifshitz et al. [1,2] and Woodruff and Sanchez-Martinez [3] reported a non-selflimiting growth for the reduction of $\mathrm{MoF}_{6}$ by $\mathrm{Si}$ at $448-673 \mathrm{~K}$ and $26-120 \mathrm{~Pa}$. Constant deposition rates in time for the reduction of $\mathrm{MoF}_{6}$ by $\mathrm{Si}$ and $\mathrm{H}_{2}$ were observed at 473-573 K and 26-120 $\mathrm{Pa}$ [2], which were described by overall reactions $\mathbf{r} . \mathbf{I}$ and $\mathbf{r} . \mathbf{I I}$

$$
\begin{aligned}
& 2 \mathrm{MoF}_{6}(g)+3 \mathrm{Si}(s) \rightarrow 2 \mathrm{Mo}(s)+3 \mathrm{SiF}_{4}(g) \\
& \mathrm{MoF}_{6}(g)+3 \mathrm{H}_{2}(g) \rightarrow \mathrm{Mo}(s)+6 H F(g)
\end{aligned}
$$

Sahin et al. studied the deposition of molybdenum by reduction of $\mathrm{MoF}_{6}$ by $\mathrm{Si}$ [4] and $\mathrm{H}_{2}$ [5] at 120 $1300 \mathrm{~Pa}$ and $523-673 \mathrm{~K}$. They observed a self-limiting reduction reaction by $\mathrm{Si}$, similar to the reduction of $\mathrm{WF}_{6}$ by $\mathrm{Si}[7,8]$. Self-limiting thicknesses of $30-130 \mathrm{~nm}$ at $130 \mathrm{~Pa}\left(\mathrm{MoF}_{6} / \mathrm{He}=1 / 3\right)$ and $523-$ $673 \mathrm{~K}$ were found. The deposition of molybdenum was $100 \%$ selective in the sense that no growth occurred on silicon oxide. The deposited layers showed extreme porosities of about $30 \%$, and high and uniform concentrations of oxygen throughout the layers.

This work reports on an in sirk study on the kinetics of the deposition of molybdenum on silicon from 
$\mathrm{MoF}_{6}$ and $\mathbf{H}_{2}$ using a microbalance setup. The major objective of this study is to measure the reaction rate of the reduction of $\mathrm{MoF}_{6}$ by $\mathrm{H}_{2}$ in the presence of the reduction of $\mathrm{MoF}_{6}$ by $\mathrm{Si}$.

\section{EXPERIMENTAL}

The microbalance LPCVD setup is designed to allow in situ measurements of the intrinsic deposition rates, i.e. the deposition rate can be monitored during the growth of the layer and the observed rate is not determined by transport phenomena in the fluidum phase. It is depicted schematically in figure 1a.
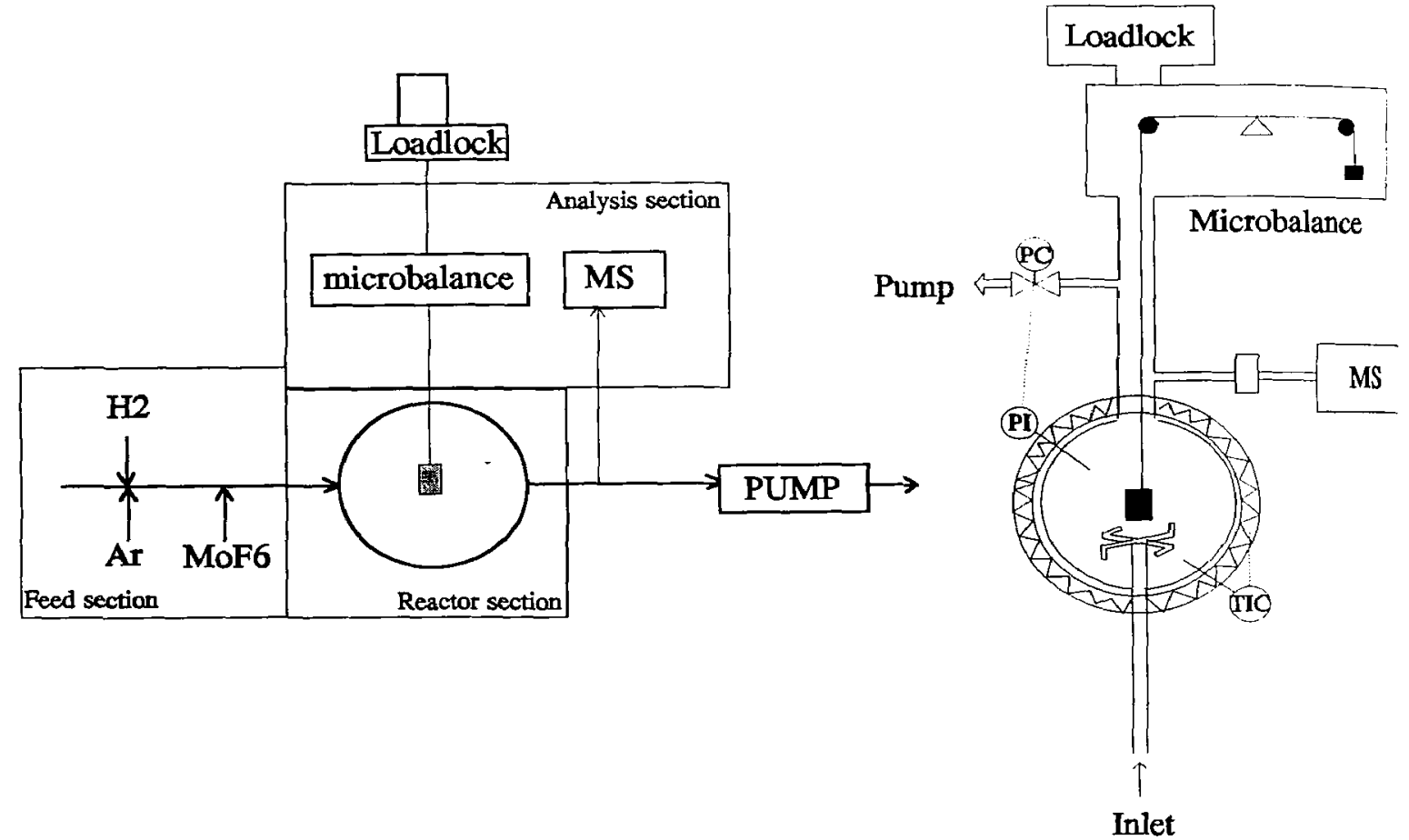

Figure 1a,b Schematic diagrams of the microbalance LPCVD setup (a), and of the reactor section (b).

In the feed section the gas mixture fed to the reactor is prepared. Reactant gas hydrogen (6.0, Air Products) and inert dilutant argon (6.0, Air Products) are mixed with molybdenum hexafluoride (3.0, Cerac) prior to introduction into the reactor. Nitrogen (6.0, Air Products) is used as purge gas. The flow rates of the $\mathrm{H}_{2}$, Ar and $\mathrm{N}_{2}$ gases are adjusted by mass flow controllers in a range varying from 2 to $100 \mathrm{sccm}$. The flow rate of $\mathrm{MoF}_{6}$ is adjustable from 1 to $20 \mathrm{sccm}$.

The reactor section consists of a hot wall quartz spherical continuous flow reactor as outlined in figure 1b. Spherical geometry was chosen because it favours mixing and uniformity of heat transfer [9]. The feed mixture is injected through four nozzles of a cross-shaped injector, located just below the centre of the reactor. The nozzles are placed midway between the centre of the reactor and the wall, in two orthogonal planes. The diameters of the reactor $\left(6.010^{-2} \mathrm{~m}\right)$ and nozzles $\left(1.810^{4} \mathrm{~m}\right)$ are chosen on the basis of hydrodynamic relations for axially symmetrical jets as proposed by David and Matras [10] to ensure good mixing. In the middle of the reactor a $15 \times 10 \mathrm{~mm}^{2}$ sized sample cul from double side polished (100) oriented silicon wafers is suspended from a microbalance by a 0.1 
mm diameter $\mathrm{NiCr}$ wire. The substrates are cleaned in boiling concentrated $\mathrm{HNO}_{3}(65 \%)$. Prior to the deposition experiments the samples receive a buffered hydrogen fluoride dip in order to remove native silicon oxide from the surface. The silicon substrates are introduced into the reactor via a loadlock. The reactor temperature is measured with a chromel-alumel (K-type) thermocouple in a thermowell located near the silicon sample. The temperature can be set between 450 and $1100 \mathrm{~K}$, and the pressure between 10 and $400 \mathrm{~Pa}$. The leak rate of the system was determined after at least a night of pumping, purging and baking the system, followed by measuring the pressure increase of the isolated system starting from $2 \cdot 10^{-3} \mathrm{~Pa}$. The leak rate amounted to about $1 \cdot 10^{-4} \mathrm{sccm}$.

The microbalance (Cahn D-200) is operated in the weight range of 0 to $20 \mathrm{mg}$. The quadrupole mass spectrometer is coupled to the reactor through an orifice with a diameter of $20 \mu \mathrm{m}$, and is used for a qualitative analysis of the gas phase at the outlet of the reactor.

Kinetic experiments were performed at a temperature of $600 \mathrm{~K}$ and total pressures from 30 to $200 \mathrm{~Pa}$. Inlet partial pressures of the reactant gases varied from 2.5 to $15 \mathrm{~Pa}$ for $\mathrm{MoF}_{6}$ and from 25 to $100 \mathrm{~Pa}$ for $\mathrm{H}_{2}$.

Grown layers were characterized ex situ using SEM, XRD and XPS. The density of the molybdenum films was determined from the film thicknesses measured with SEM and the weight differences of the samples after dissolution of the molybdenum in boiling concentrated $\mathrm{H}_{2} \mathrm{SO}_{4}$.

\section{RESULTS AND DISCUSSION}

\subsection{Microbalance results}

Figure 2 presents the results of a typical experiment. The mass increase is reported per geometric surface area of the sample. In contrast to the results presented by Lifshitz et al. [2] a nonlinear dependence of the film thickness on time is observed. The deposition rates do not become constant, even not after 30 minutes when a thickness of typically $3 \mu \mathrm{m}$ is reached. The mass spectrometer spectra show main product peaks at $\mathrm{m} / \mathrm{e}=85$ and $\mathrm{m} / \mathrm{e}=20$, corresponding to $\mathrm{SiF}_{4}$ and HF respectively. This is consistent with overall reactions $\mathbf{r . I}$ and $\mathbf{r . I I}$.

Attempts were made to study both reactions separately by depositing molybdenum by reduction of $\mathrm{MoF}_{6}$ by $\mathrm{Si}$ in the absence of $\mathrm{H}_{2}$ and by reduction of $\mathrm{MoF}_{6}$ by $\mathrm{H}_{2}$ in the absence of

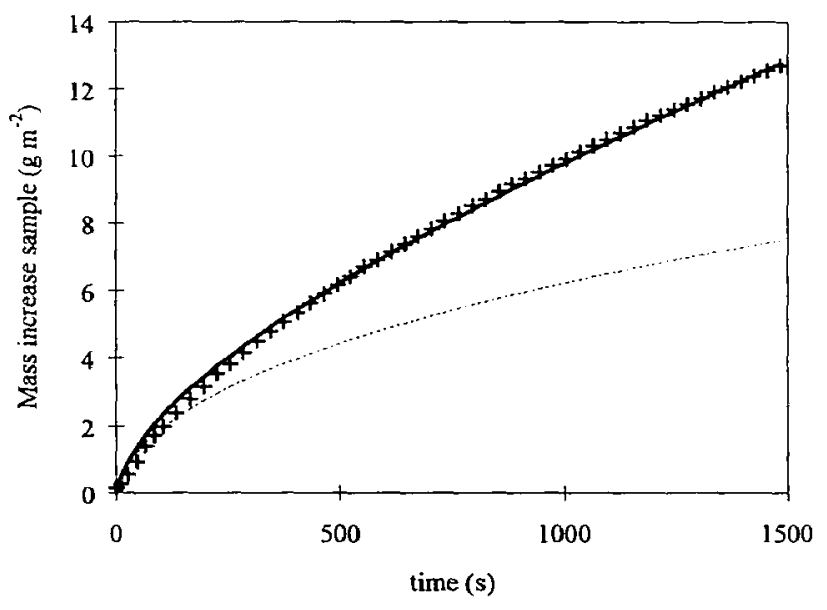

Figure 2. A typical mass versus time curve, + experimental, calculated with the model in $3.3\left(D_{s i, e f f}=2.08 \pm 0.01 \cdot 10^{-15} \mathrm{~m}^{2} \mathrm{~s}^{-1}\right.$;

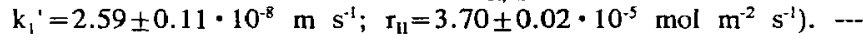
calculated contribution of r.I. Conditions: $T=600 \mathrm{~K} ; \mathrm{p}_{\mathrm{H} 2}^{\circ}=75 \mathrm{~Pa}$; $\mathrm{p}_{\text {MoFo }}^{\circ}=5 \mathrm{~Pa} ; \mathrm{p}^{\circ}{ }_{\mathrm{At}}=0 \mathrm{~Pa}$. $\mathrm{Si}$, using other types of surfaces. However the reduction of $\mathrm{MoF}_{6}$ by $\mathrm{Si}$ solely was irreproducible, while attempts to grow on other types of surfaces, like sputtered $\mathrm{Pt}$, sputtered Mo, LPCVD-W and sputtered Ti lead to no growth at all, severe etching, or the same type of time dependent deposition rates as found for Mo-CVD on Si.

\subsection{Film characteristics}

XRD patterns exhibit only crystalline molybdenum in the deposited layer (figure 3), while from SEM photographs it can be concluded that the layer consists of polycrystalline material with grain sizes of about $0.1 \mu \mathrm{m}$ (figure 5). The density of the layers amounted to about $70 \%$ of the density of bulk molybdenum, which equals the density found by Lifshitz et al. [1,2]. XPS measurements on a molyb- 
denum film with a thickness of even $5 \mu \mathrm{m}$ showed a small amount of $\mathrm{Si}$ in the upper atomic layers of the deposited molybdenum (figure 4). The binding energy of $104 \mathrm{eV}$ in the Si $2 p$ spectrum corres. ponds to silicon oxide, which is probably formed during transport of the sample to the XPS apparatus.

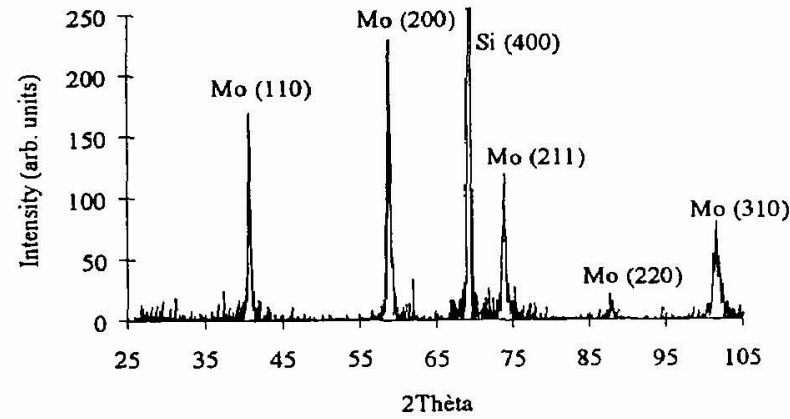

Figure 3. CuK $\alpha 1-\mathrm{XRD}$ of a CVD grown Mo layer $\left(\mathrm{T}=600 \mathrm{~K} ; \mathrm{P}_{\text {MOFG }}^{\circ}=5 \mathrm{~Pa} ; \mathrm{P}_{\mathrm{H} 2}^{\circ}=75 \mathrm{~Pa}\right)$.

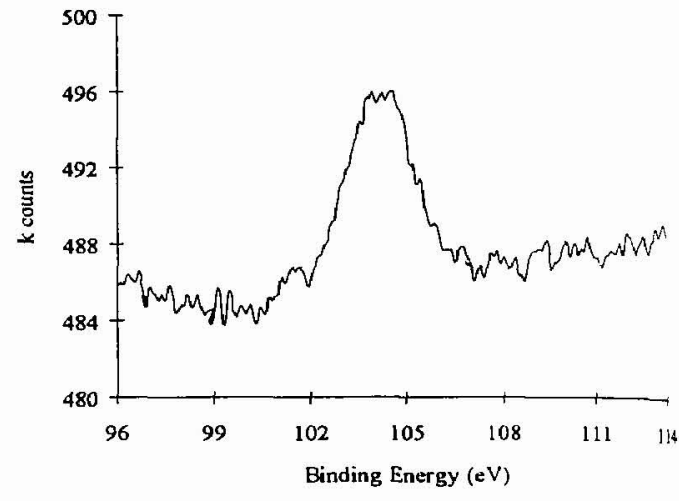

Figure 4. XPS spectrum of the Si $2 p$ region of the surface of a Mo layer $\left(\mathrm{T}=600 \mathrm{~K} ; \mathrm{p}^{\circ}{ }_{\mathrm{MoF} 6}=10 \mathrm{~Pa} ; \mathrm{p}_{\mathrm{H} 2}^{\mathrm{a}}=50 \mathrm{~Pa}\right)$

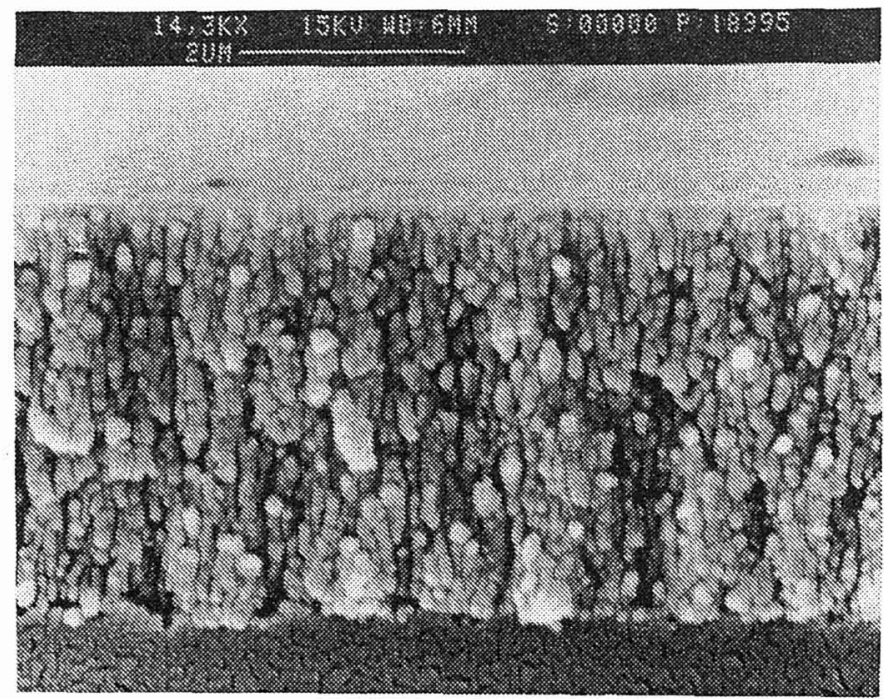

Figure 5. SEM photograph of a typical Mo layer grown at $600 \mathrm{~K}, \mathrm{p}_{\text {MoFo }}^{\circ}=5 \mathrm{~Pa}$ and $\mathrm{p}_{\mathrm{H} 2}^{\circ}=50 \mathrm{~Pa}$ during $3000 \mathrm{~s}$.

\subsection{Model equations}

The time dependent growth behaviour of molybdenum by the reduction of $\mathrm{MoF}_{6}$ by $\mathrm{Si}$ and $\mathrm{H}_{2}$ can be explained by a model which takes into account the diffusion of elemental Si through the growing molybdenum layer at a finite rate. As the layer grows, the diffusion length of Si increases, leading to a 
decreasing $\mathrm{Si}$ concentration on the reacting surface and correspondingly to a decrease of the rate of reaction $\mathbf{r . I}$, if the reactions are assumed to take place at the external gas-solid interface. As the mass versus time curve in a typical experiment still deflects after even $1500 \mathrm{~s}$ (figure 2), reaction r.I may be expected to play a significant role in the deposition process. This model is also consistent with the $\mathrm{Si}$ in the upper atomic layers observed with XPS and the Si profile through grown molybdenum layers observed by Lifshitz et al using SIMS [1]. The observed low density can then, at least partially, be explained by the large amounts of $\mathrm{Si}$ in the layer. Diffusion of $\mathrm{MoF}_{6}$ and/or $\mathrm{H}_{2}$ through the growing layer is not considered.

Figure 6 shows a schematic presentation of the model which is applied to account for contributions of both reactions r.I and r.II and, hence, allows to study the dependence of the reduction of $\mathrm{MoF}_{6}$ by $\mathrm{H}_{2}$ on the reaction conditions. The properties of the grown layer, the temperature at the surface, and the gas phase concentrations of the reactants at the surface are assumed to be constant in time. Low conversions of the reactants $(<15 \%)$ indicate differential operation of the reactor, so the bulk gas phase concentrations are considered equal to the inlet concentrations. Ignoring mass transfer limitations is allowed because of the low Dam-

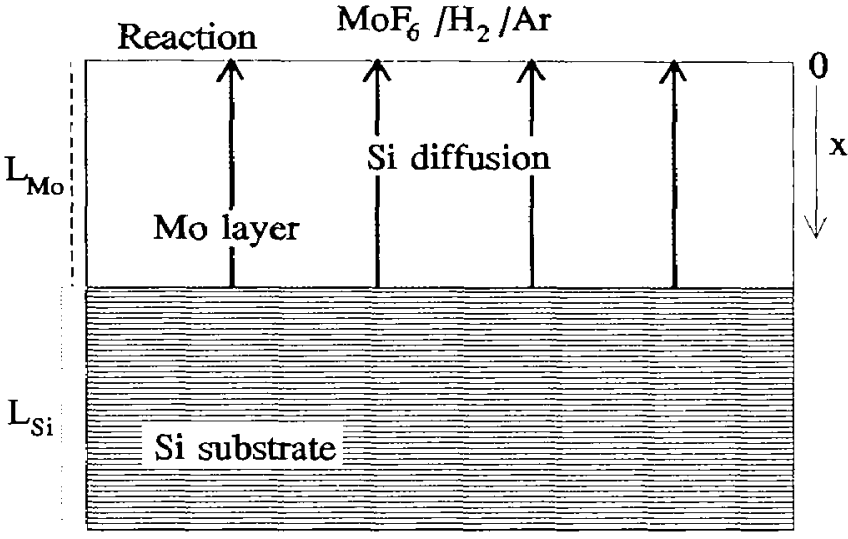

Figure 6. Schematic presentation of the model. kohler II number $\left(\mathrm{r}_{\mathrm{obs}} \mathrm{L} / \mathrm{D}_{\mathrm{MoF} 6} \mathrm{C}_{\mathrm{MoF} \sigma}\right.$ ), which is equal to the time scale of transport compared to the time scale of surface reaction; even when the former is based on the reactor radius $\mathrm{L}, \mathrm{Da}_{11}<0.05$.

The quantity measured with the microbalance is equal to the net mass increase of the sample, $\Delta \mathrm{m}$, which is a summation of the production of molybdenum minus the consumption of $\mathrm{Si}$ :

$$
\frac{\Delta m}{A}=L_{M o} \rho_{M o}-\left(L_{S i, 0}-L_{S i}\right) \rho_{S i}
$$

where $\mathrm{A}$ is the substrate area, $\mathrm{L}_{\mathrm{Mo}}$ and $\mathrm{L}_{\mathrm{Si}, 0}-\mathrm{L}_{\mathrm{Si}}$ are the thicknesses of the produced molybdenum layer and consumed $\mathrm{Si}$ respectively, and $\rho_{\mathrm{Mo}}$ and $\rho_{\mathrm{Si}}$ are the densities of the molybdenum and silicon.

The thickness of the molybdenum layer can be calculated from the molybdenum mass balance:

$$
\frac{\rho_{M o}}{M_{M o}} \frac{d L_{M o}}{d t}=r_{i}+r_{H}
$$

with initial condition $\mathrm{L}_{\mathrm{M}_{0}}=0$ and $\mathrm{r}_{\mathrm{I}}=2 / 3 \mathrm{k}_{\mathrm{l}}{ }^{\prime} \mathrm{C}_{\mathrm{Si}} \mathrm{l}_{\mathrm{O}}$. A first order dependency in the concentration of elemental $\mathrm{Si}$ at the surface, $\mathrm{C}_{\mathrm{Si}} \mathrm{I}_{0}$, is assumed for the reduction reaction by $\mathrm{Si}$. The factor $2 / 3$ accounts for the reaction stoichiometry. As the gas phase concentrations above the surface are constant during an experiment, the pseudo first order reaction coefficient of the reduction by $\mathrm{Si}, \mathrm{k}_{\mathrm{l}}{ }^{1}\left(\mathrm{~m} \mathrm{~s}^{-1}\right)$, and the

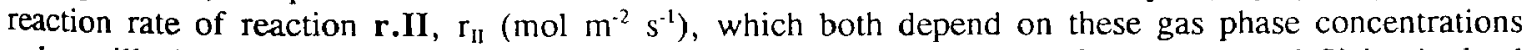
only, will also remain constant during this experiment. The thickness of the consumed $\mathrm{Si}$ is obtained from the silicon mass balance:

$$
\frac{\rho_{S i}}{M_{S i}} \frac{d\left(L_{S i, 0}-L_{S i}\right)}{d t}=\left.k_{1}^{\prime} C_{S i}\right|_{o}
$$

with initial condition $\mathrm{L}_{\mathrm{si}}=\mathrm{L}_{\mathrm{Si},(i)}$. 
The concentration of elemental $\mathrm{Si}$ at the surface $\mathrm{C}_{\mathrm{Si}} \mathrm{I}_{0}$ can be calculated from the continuity equation for $\mathrm{Si}$ in the growing layer:

$$
\frac{\partial C_{S i}}{\partial t}=D_{S i, e f f} \frac{\partial^{2} C_{S i}}{\partial x^{2}}
$$

with initial condition $\mathrm{C}_{\mathrm{si}} \mathrm{I}_{\mathrm{t}=0}=\mathrm{C}_{\mathrm{si}, \text { bulk}}$, and boundary conditions:

$$
\begin{aligned}
& \left.C_{S i}\right|_{L(t)}=C_{S i, b u l k} \\
& \left.D_{S i, \mathscr{J}} \frac{\partial C_{S i}}{\partial x}\right|_{0}=\left.k_{1}^{\prime} C_{S i}\right|_{0}
\end{aligned}
$$

where $D_{\text {sieff }}$ is the effective diffusion coefficient of $\mathrm{Si}$ through the growing molybdenum layer $\left(\mathrm{m}^{2} \mathrm{~s}^{-1}\right)$ and $\mathrm{C}_{\mathrm{Si}, \text { bulk }}$ is the $\mathrm{Si}$ concentration in the sample. The first boundary condition simply states that the $\mathrm{Si}$ concentration at the $\mathrm{Mo} / \mathrm{Si}$ interface is equal to the concentration in the substrate, while according to the second boundary condition the flux of $\mathrm{Si}$ to the surface is equal to the consumption of $\mathrm{Si}$ on that surface.

This model is solved numerically using routine D03PJF from the NAG-library [11], and is coupled to the non-linear regression Marquardt routine [12]. In this routine regression of measured mass increase data to obtain maximum likelihood estimates for $\mathrm{D}_{\mathrm{si}, \mathrm{eff}}, \mathrm{k}_{1}{ }^{\prime}$ and $\mathrm{r}_{\mathrm{Il}}$ is performed by application of the least square criterion to the observed and calculated mass increases.

\subsection{Kinetics of molybdenum deposition from $\mathrm{MoF}_{6}$ and $\mathrm{H}_{2}$}

Figure 2 shows a typical growth curve together with the growth curve calculated with the model using estimated parameters values. As can be seen the model describes the experiment very well. The net mass increase at $t=1500 \mathrm{~s}$ is calculated from the slope of the measured curve to be $5.5 \cdot 10^{-3} \mathrm{~g} \mathrm{~m}$ ${ }^{2} \mathrm{~s}^{-1}$, while the estimated rate of reaction $\mathrm{r}$.II, $\mathrm{r}_{\mathrm{II}}$, amounts to $3.5 \cdot 10^{-3} \mathrm{~g} \mathrm{~m}^{-2} \mathrm{~s}^{-1}$. So the reduction of $\mathrm{MoF}_{6}$ by Si still accounts for $36 \%$ of the nett overall mass increase after $1500 \mathrm{~s}$ and, thus, cannot be neglected. This is also shown in figure 2 by the curve of the contribution of r.I.

The effective diffusion coefficient of $\mathrm{Si}$ through the layer, $\mathrm{D}_{\mathrm{si}, \text { eff }}$, varies from one experiment to the other in the range of $6 \cdot 10^{-16}-4 \cdot 10^{-15} \mathrm{~m}^{2} \mathrm{~s}^{-1}$; a distinct trend could not be observed. These values are of the same order of magnitude as those used by Joshi et al. [6], to describe the non-self-limiting deposition of tungsten by reduction of $\mathrm{WF}_{6}$ by $\mathrm{Si}$. They compared the CVD of tungsten by reduction of $\mathrm{WF}_{6}$ by $\mathrm{Si}$ in a UHV system with the CVD of tungsten in a commercial LPCVD reactor. The growth of tungsten in both systems appeared to be non-self-limiting, showing a non-linear dependence of the grown layer thickness on time. The films grown in the LPCVD reactor however were much thicker. They also found large oxygen concentrations in the LPCVD grown layers, a gradient of elemental Si throughout the layers, and a density for LPCVD grown tungsten equal to $60-70 \%$ and for UHV grown films equal to $90-100 \%$ of the density of bulk tungsten. The grown films were microcrystalline and nonporous. The differences between UHV and LPCVD were attributed to the relatively high levels of water vapour present in the LPCVD reactor, leading to the formation of a finegrained W structure surrounded by a W-O layer, which assists faster diffusion of $\mathrm{Si}$ through the tungsten films compared to the UHV system. So, the results presented in 3.1 and 3.2 are very similar to those presented by Joshi et al., who attributed these to the presence of water contamination in the reactor. It can therefore not be excluded that different background pressures of water vapour in the microbalance setup are responsible for the large range of effective diffusion coefficients found. 
The pseudo first order reaction coefficient $\mathrm{k}_{1}{ }^{\prime}$ was large, ranging from $10^{-8}$ to $10^{-7} \mathrm{~m} \mathrm{~s}^{-1}$, compared to the diffusion rate of $\mathrm{Si}, \mathrm{D}_{\mathrm{Si}, \mathrm{cf}} / \mathrm{L}_{\mathrm{Mo}_{0}}<10^{-8} \mathrm{~m} \mathrm{~s}^{-1}$ within $60 \mathrm{~s}$, and hardly influenced the regression. As diffusion of $\mathrm{Si}$ through the growing layer and reaction of $\mathrm{Si}$ with $\mathrm{MoF}_{6}$ at the gas-solid interface are consecutive steps, the former obviously will become the rate determining step in reaction r.I, when the diffusion length of the silicon, $\mathrm{L}_{\text {Mo }}$, becomes sufficiently long, typically after one minute.
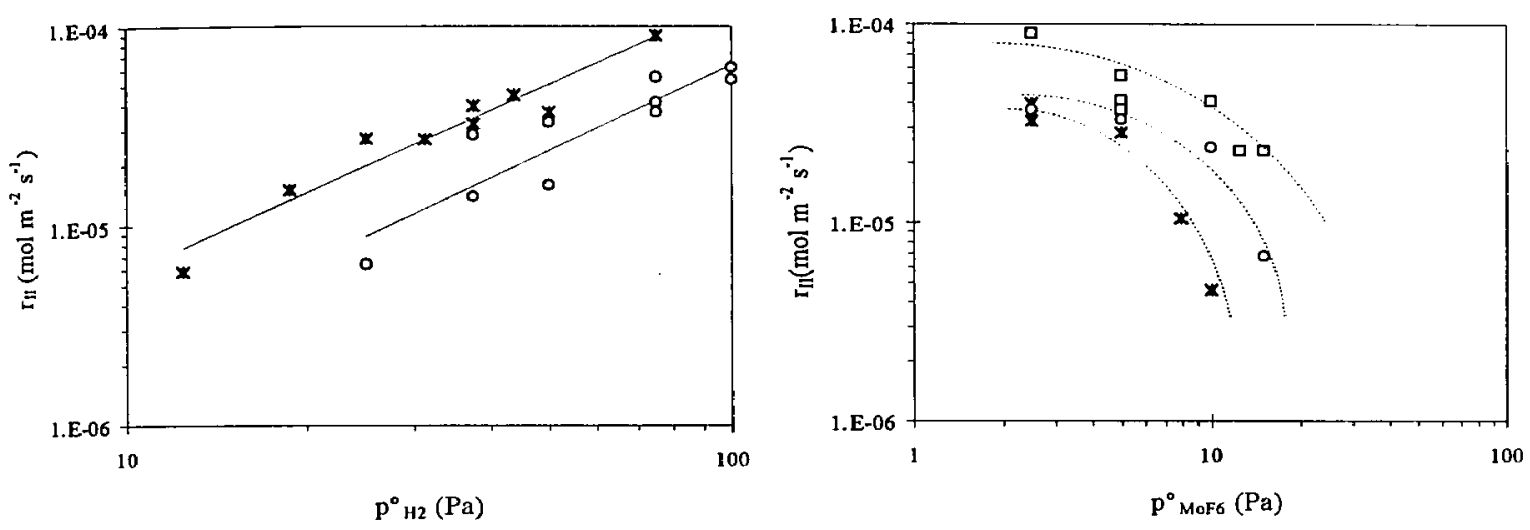

Figure 7 Reaction rate $\mathrm{r}_{\mathrm{Il}}$ as a function of $\mathrm{p}_{\mathrm{H} 2}^{\circ}$ (a) and $\mathrm{p}_{\mathrm{MoF}}^{\circ}$ (b). a. $\mathrm{T}=600 \mathrm{~K} ; \mathrm{O} \mathrm{p}_{\mathrm{MoF} 6}^{\circ}=5.0 \mathrm{~Pa}$ and $* \mathrm{p}_{\text {MoF6 }}^{\circ}=2.5 \mathrm{~Pa}$. b. $\mathrm{T}=600 \mathrm{~K},{ }^{*} \mathrm{p}_{\mathrm{H} 2}^{\circ}=37.5 \mathrm{~Pa}, \bigcirc \mathrm{p}_{\mathrm{H} 2}^{\circ}=50.0 \mathrm{~Pa}$ and $\square \mathrm{p}^{\circ}{ }_{\mathrm{H} 2}=75.0 \mathrm{~Pa}$.

Figures $7 \mathrm{a}$ and $7 \mathrm{~b}$ show the reaction rate of reduction of $\mathrm{MoF}_{6}$ by $\mathrm{H}_{2}, \mathrm{r}_{11}$, as a function of the $\mathrm{H}_{2}$ and $\mathrm{MoF}_{6}$ partial pressures respectively. The dependency of $\mathrm{r}_{1 \mathrm{II}}$ in $\mathrm{p}^{\circ}{ }_{\mathrm{H} 2}$ corresponds to a partial reaction order of about 1.4 , while that in $\mathrm{p}_{\text {MoF6 }}^{\circ}$ is slightly negative at low $\mathrm{p}_{\text {MoF } 6}^{\circ}$ and becomes strongly negative at higher $\mathrm{p}^{\circ}{ }_{\text {MoF6 }}$. The partial reaction orders in $\mathrm{p}^{\circ}{ }_{\text {MoF } 6}$ are similar to the results reported by Creighton [14], who studied the deposition of tungsten from $W F_{6}$ and $\mathrm{H}_{2}$ using the microbalance technique. Creighton observed a partial reaction order in $\mathrm{p}^{\circ}{ }_{\text {wF }}$ ranging from nearly zero to strongly negative values, and a partial reaction order in $\mathrm{P}_{\mathrm{H} 2}^{\circ}$ ranging from $1 / 2$ to values appreciably higher than one. The negative values of the partial reaction order in $\mathrm{p}^{\circ}{ }_{\mathrm{wF} 6}$ become more pronounced at lower $\mathrm{p}_{\mathrm{H} 2}^{\circ}$. A simple reaction mechanism based on the Langmuir-Hinshelwood model was used to explain these results. At high $\mathrm{p}^{\circ}{ }_{\text {wF }}$ the surface is believed to be mainly occupied by adsorbed fluorine from $W F_{x}$, which inhibites chemisorption of $\mathrm{H}_{2}$. Dissociative adsorption of $\mathrm{H}_{2}$ then becomes the rate determining step, leading to a first order dependence in $\mathrm{p}_{\mathrm{H} 2}^{\circ}$ and a minus one order in $\mathrm{p}^{\circ} \mathrm{wFr}^{\circ}$. At sufficiently high $\mathrm{p}_{\mathrm{H} 2}^{\circ}$ the dependency in $\mathrm{p}_{\mathrm{H} 2}^{\circ}$ is expected to become negative, while the deposition rate will show a first order dependence in $\mathrm{p}_{\mathrm{wF} \sigma}^{\circ}$, according to the proposed mechanism. Ammerlaan [15] suggests that the mechanisms proposed by McConica and Krishnamani [7], and by Pauleau and Lami [16] may even lead to partial reaction orders in $\mathrm{p}^{\circ}{ }_{\mathrm{WF} 6}$ as low as minus two at low $\mathrm{p}^{\circ}{ }_{\mathrm{H} 2}$. In addition etching of tungsten by $\mathrm{WF}_{6}$ can account for deviations in the observed orders at low $\mathrm{p}^{\circ}{ }_{\mathrm{H} 2}$ [14].

The partial reaction orders in the present work are not consistent with the partial reaction orders of $1 / 2$ in $\mathrm{p}_{\mathrm{H} 2}^{\circ}$ and 0 in $\mathrm{p}_{\mathrm{MOF} 6}^{\circ}$ reported by Sahin et al. [5]. A possible explanation for these differences is that Sahin et al. used a cold wall reactor for their deposition experiments in which transport phenomena, like thermal diffusion, can easily obscure intrinsic kinetics [13]. Thermal diffusion causes heavy species like $\mathrm{MoF}_{6}$ to diffuse away from the heated wafer surface, leading to a significant lower $P^{\prime \prime}$ Mor 6 above the substrate. Therefore the actual conditions above the reacting surface can easily shift towards higher $\mathrm{p}_{\mathrm{H} 2} / \mathrm{p}_{\mathrm{Mol} \text {, }}$ ratios then the ratio at the inlet of the reactor. According to the mechanisms mentioned above a higher order in $\mathrm{P}_{\mathrm{M} N \mathrm{i}}$ and a lower order in $\mathrm{P}_{\mathrm{H} 2}^{\prime \prime}$ can then be expected. 


\section{CONCLUSIONS}

A microbalance setup was used to study the kinetics of molybdenum deposition on silicon from $\mathrm{MoF}_{6}$ and $\mathrm{H}_{2}$. The significant contribution of the reaction of $\mathrm{MoF}_{6}$ with $\mathrm{Si}$ to the overall molybdenum deposition rate obscures the intrinsic kinetics of the reduction of $\mathrm{MoF}_{6}$ by $\mathrm{H}_{2}$. In order to separate both reaction pathways, a model was developed taking into account diffusion of $\mathrm{Si}$ through the growing layer. Integrating numerically the model and applying a non-linear regression a partial reaction order of 1.4 in hydrogen was found for the reduction of $\mathrm{MoF}_{6}$ by $\mathrm{H}_{2}$. The order in $\mathrm{MoF}_{6} \mathrm{for}_{0}$ this reaction is negative.

\section{REFERENCES}

[1] Lifshitz N. and Green M.L., J. Electrochem. Soc., 135 (1988) 131-136.

[2] Lifshitz N., Williams D.S., Capio C.D. and Brown J.M., J. Electrochem. Soc, 134 (1987) 2061-2067.

[3] Woodruff D.W. and Sanchez-Martinez R.A., "CVD Molybdenum from MoF 6 ", Tungsten and Other Refractory Metals for VLSI Applications II, 1986, E.K. Broadbent Ed. (Materials Research Society, Pittsburgh, PA 1987) pp. 207-213.

[4] Sahin T. and Park C.-S., "Low Pressure Chemical Vapour Deposition of Molybdenum by Silicon Reduction of $\mathrm{MoF}_{6} "$ ", Tungsten and Other Refractory Metals for VLSI Applications IV, 1988, R.S. Blewer and C.M. McConica Eds. (Materials Research Society, Pittsburgh, PA 1989) pp. 253-256.

[5] Sahin T., Flanigan E.J. and Sears J.T., "Low Pressure Chemical Vapour Deposition of Molybdenum: 1. Kinetics and Reaction Mechanisms", Tungsten and Other Refractory Metals for VLSI Applications II, 1986, E.K. Broadbent Ed. (Materials Research Society, Pittsburgh, PA 1987) pp. 199-205.

[6] Joshi R.V., Prasad V., Yu M.L., Scilla G., J. Appl. Phys., 71 (1992) 1428-1441.

[7] Broadbent E.K., Ramiller C.L., J. Electrochem. Soc., 131 (1984) 1427-1433.

[8] McConica C.M. and Krishnamani K., J. Electrochem. Soc., 133 (1986) 2542-2548.

[9] Weerts W.L.M., "Low Pressure CVD of Polycrystalline Silicon: Reaction Kinetics and Reactor Modelling", Ph. D. Thesis, University of Technology Eindhoven, Eindhoven, to be published, 1995.

[10] David R. and Matras D., Can. J. Chem. Eng., 53 (1975) 297-300.

[11] NAG Ltd, Fortran Library Manual, \# 15, (Wilkinson House, Oxford, 1991).

[12] Marquardt D.W., J. Soc. Indust. Appl. Math., 11 (1963) 431-441.

[13] Kleijn, C.R., "Transport Phenomena in Chemical Vapor Deposition reactors", Ph. D. Thesis, Delft University of Technology, Delft, 1991.

[14] Creighton J.R., Thin solid films, 24 (1994) 310-317.

[15] Ammerlaan J.A.M., "Kinetics and Characterization of Tungsten CVD Processes", Ph. D. Thesis, Delft University of Technology, Delft, 1994.

[16] Pauleau Y. and Lami Ph., J. Electrochem. Soc., 132 (1985) 2779-2784. 